Magdalena Krintus ${ }^{1}$, Marek Koziński², Sławomir Manysiak ${ }^{1}$, Lena Nowak-Łoś ${ }^{1}$, Lieselotte Lennartz ${ }^{3}$, Jessie Shih" ${ }^{4}$, Ewa Laskowska², Ewa Janiszewska ${ }^{5}$, Jacek Kubica6 ${ }^{6}$, Grażyna Odrowąż-Sypniewska ${ }^{1}$

${ }^{1}$ Department of Laboratory Medicine, Nicolaus Copernicus University, Collegium Medicum in Bydgoszcz, Poland

2Department of Principles of Clinical Medicine, Nicolaus Copernicus University, Collegium Medicum in Bydgoszcz, Poland

${ }^{3}$ Abbott Laboratories, Wiesbaden, Germany

${ }^{4}$ Abbott Laboratories, Abbott Park, IL, United States

${ }^{5}$ Department of Pharmacology and Therapeutics, Nicolaus Copernicus University, Collegium Medicum in Bydgoszcz, Poland

${ }^{6}$ Department of Cardiology and Internal Medicine, Nicolaus Copernicus University, Collegium Medicum in Bydgoszcz, Poland

\title{
ARCHITECT STAT High Sensitive Troponin I Familiarization Study (FAM) in the Department of Laboratory Medicine, Collegium Medicum, Nicolaus Copernicus University in Bydgoszcz, Poland
}

\author{
Corresponding author: \\ Magdalena Krintus, MD, PhD, \\ Department of Laboratory Medicine, \\ Nicolaus Copernicus University, \\ Collegium Medicum \\ 9 Sklodowskiej-Curie Street \\ 85-094 Bydgoszcz, Poland \\ Phone: +48525853602 \\ Fax: +48525853603 \\ E-mail: krintus@wp.pl
}

Folia Medica Copernicana 2015; Volume 3, Number 3, 107-112 10.5603/FMC.2015.0004 Copyright (C) 2015 Via Medica ISSN 2300-5432

\begin{abstract}
Background. International guidelines recommend the use of cardiac troponin assays for early detection of acute myocardial infarction. New high-sensitivity assays along with improved precision and sensitivity, are now widely available, accelerating patient's diagnosis, treatment and invasive therapy. In this study we evaluated analytical performance of the Abbott ARCHITECT STAT high-sensitive troponin-I immunoassay and its $99^{\text {th }}$ percentile upper reference limit.

Methods. We performed the analytical evaluation of the hs-cTnl assay using Abbott ARCHITECT $i 2000_{\text {SR }}$ immunoanalyzers. Features of the assay including imprecision, detection limits, linearity of dilution, interferences and method comparisons were assessed, as well as the $99^{\text {th }}$ percentile upper reference limits in a cohort of 427 presumably healthy individuals were established.

Results. Total imprecision ranged from $3.1 \%$ to $4.7 \%$ and was lowest for the medium controls. The observed limit of blank, limit of detection and limit of quantitation assumed values of $0.1,1.5$ and $4.8 \mathrm{ng} / \mathrm{L}$, respectively. Common interferences, sample dilution and carry over did not affect the hs-cTnl results. Hs-cTnl was detectable in $98 \%$ of presumably healthy individuals. The $99^{\text {th }}$ percentile values were age and sex dependent in the presumably healthy, but not in the healthy individuals.

Conclusion. The new high-sensitivity troponin-I assay has improved analytical features and may be a valuable diagnostic tool.

Key words: analytical performance, high sensitivity troponin, $99^{\text {th }}$ percentile URL
\end{abstract}

Folia Medica Copernicana 2015; 3 (3): 107-112

\section{Introduction}

The primary role for cardiac troponin (cTn) assays, since its introduction have been to diagnose patients with acute myocardial infarction (AMI) [1-3]. Due to this, international guidelines recommend the use of high-sensitivity cTn (hs-cTn) assays for early detection of AMI [3]. New high-sensitivity assays with improved precision and sensitivity are now widely available improving the ability to detect cardiomyocyte injury and accelerating patient's diagnosis, treatment and invasive therapy [4]. Another advantage of hs-cTnl assays, in addition to a rapid diagnosis of patients with suspected acute coronary syndromes (ACS), is the ability to measure the concentrations of cTn in the majority of healthy individuals, which may contribute to its role 
in primary prevention and long-term assessment of adverse events.

The study was designed and supervised in the Department of Laboratory Medicine in cooperation with clinicians from the Department of Cardiology and Internal Medicine, Collegium Medicum in Bydgoszcz, Nicolaus Copernicus University in Torun. Laboratory tests were performed in the Department of Laboratory Medicine, Antoni Jurasz University Hospital No. 1 in Bydgoszcz, which is the region's largest specialized medical facility and is of regional importance. The hospital's organizational structure consists of 26 departments and units (940 beds in total), 6 diagnostic divisions and specialist outpatient clinics. The hospital annually admits approximately 37,000 patients and providing 170,000 specialist consultations.

The Department of Laboratory Medicine is part of Antoni Jurasz University Hospital and is headed by Professor Grażyna Odrowąż-Sypniewska. For the last 10 years the laboratory has participated in the Randox International Quality Assessment Scheme (RIQAS) and in the Central National Laboratory Program, and is certified by these bodies.

The laboratory is equipped with high quality medical equipment enabling us to perform tests in the fields of clinical chemistry, immunochemistry, hematology, body fluid analysis, toxicology, allergology and other highly specialized research.

The purpose of the study was:

1. To evaluate the analytical performance of the Abbott ARCHITECT STAT High Sensitive Troponin-I assay following CLSI guidelines EP5-A2 for precision [5], EP17-A for limit of blank (LoB), limit of detection (LoD) and limit of quantitation (LoQ) [6] and EP6-A for linearity [7] on the ARCHITECT ci8200.

2. To establish the 99th percentile upper reference limit (URL) for hs-cTnl in presumably healthy and healthy individuals.

3. To compare specimen results obtained with the Abbott ARCHITECT STAT High Sensitive Troponin-I assay with the ARCHITECT STAT Troponin-I assay using a minimum of 150 specimens with cTnl concentrations across the dynamic range of the assay.

\section{Materials and methods}

\section{Study design and performance}

After the study protocol was approved by the Bioethics Committee of the Collegium Medicum, Nicolaus Copernicus University in Torun, we started recruiting presumably healthy subjects. Blood sampling was carried out in several workplaces across the region. Serum and plasma samples were obtained from presumably healthy individuals who declared good health in the questionnaires, completed by each individual prior to sampling. The presumably healthy reference population was defined as individuals who were free of cardiac diseases (had no history of cardiac disease, cardiac treatment, cardiac intervention), hypertension, diabetes mellitus or hyperlipidemia. Additionally, the following inclusion criteria were defined as follows: BNP $<25 \mathrm{pg} / \mathrm{mL}$ for males and $<40 \mathrm{pg} / \mathrm{mL}$ for females; eGFR $>90 \mathrm{~mL} / \mathrm{min}$ for aged below 40 and $>60 \mathrm{~mL} / \mathrm{min}$ for those aged over 41 ; $\mathrm{HbA}_{1 \mathrm{c}}<6.5 \%$. Dyslipidemia was defined by at least one abnormal level of serum lipid parameters: total cholesterol $(\mathrm{TC})>200 \mathrm{mg} / \mathrm{dL}$, triglyceride $(\mathrm{TG})>150 \mathrm{mg} / \mathrm{dL}$, LDL-cholesterol (LDL-C) $>130 \mathrm{mg} / \mathrm{dL}$, HDL-cholesterol (HDL-C) $<50 \mathrm{mg} / \mathrm{dL}$ for women and $<40 \mathrm{mg} / \mathrm{dL}$ for men according to the modified definition in the Third Report of the National Cholesterol Education Program [8]. Hypertension was diagnosed if systolic blood pressure exceeded $140 \mathrm{~mm} \mathrm{Hg}$ and/or diastolic blood pressure was above $90 \mathrm{~mm} \mathrm{Hg}$. Blood pressure measurements were obtained if needed. Additional exclusion criteria included pregnancy, current infection and chronic inflammatory disease.

The $99^{\text {th }}$ percentile values for hs-cTnl in a reference population were determined in two defined groups: presumably healthy and healthy, respectively. The 427 participants were defined as presumably healthy on the basis of criteria from a health questionnaire. We initially excluded eight individuals who did not meet the inclusion criteria in the study, 3 of them were identified as outliers. The final study group consisted of 418 presumably healthy subjects ( 265 females and 153 males, aged 17-74). The next step of our analysis included 320 healthy subjects (212 females and 108 males, aged 17-65) who fulfilled the requirements of the study according to the main inclusion and exclusion criteria, and based on predefined laboratory measurements. The final step in the analysis was to evaluate the $99^{\text {th }}$ percentile URLs for hs-cTnl in healthy subjects who remained after excluding those with dyslipidemia. This study group consisted of 136 subjects (106 females and 30 males, aged 17-63). The study design is shown in Figure 1.

\section{Blood sampling and laboratory analyses}

Fasting venous blood samples from presumably healthy individuals were collected in the morning. All participants had given informed consent for study participation. Blood samples were collected into a $6 \mathrm{~mL}$ tube without anticoagulant (Becton Dickinson) to obtain serum and two $2 \mathrm{~mL}$ EDTA tubes (Becton Dickinson) in order to determine the $\mathrm{HbA}_{1 \mathrm{c}}$ in whole blood and obtain plasma for determination of BNP. Serum was 


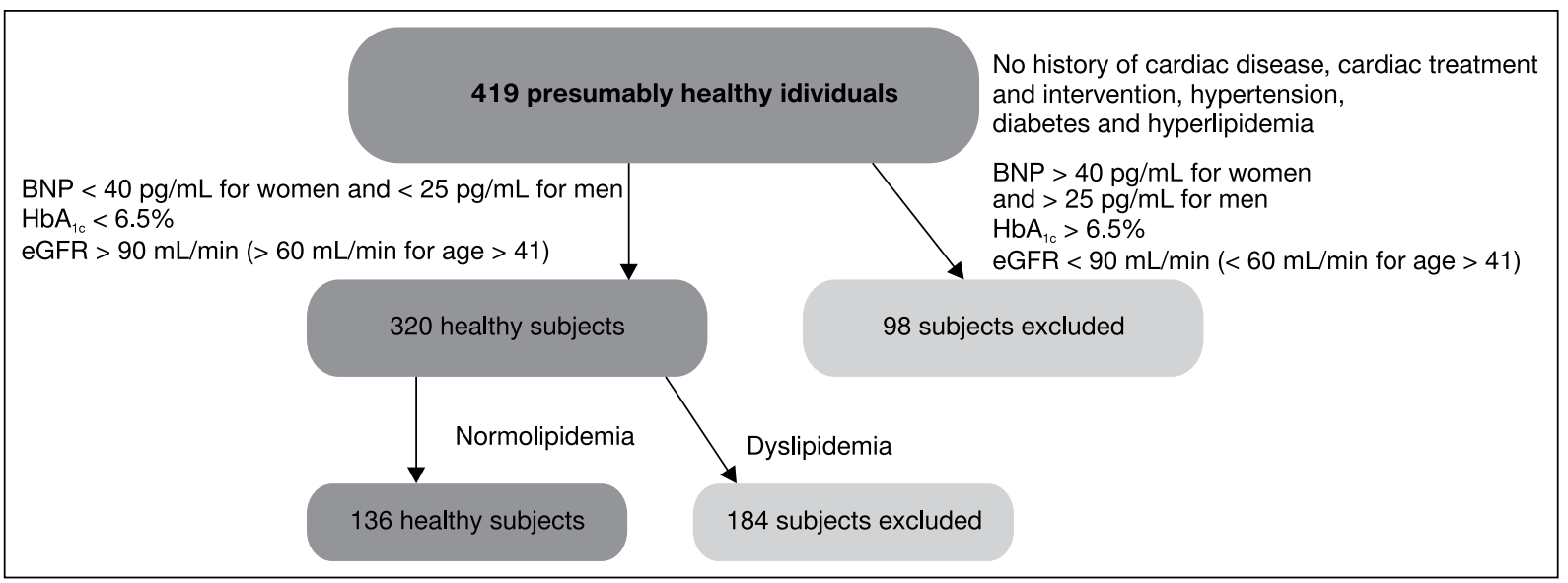

Figure 1. The FAM study design in the Department of Laboratory Medicine, Collegium Medicum in Bydgoszcz; $\mathrm{BNP}$ - brain natriuretic peptide; $\mathrm{HbA}_{1 \mathrm{c}}$ - glycated haemoglobin; eGFR - estimated glomerular filtration rate

Table 1. Control measurements at three levels

\begin{tabular}{lccc}
\hline $\begin{array}{l}\text { Control } \\
\text { level }\end{array}$ & $\begin{array}{c}\text { Troponin I } \\
\text { validity range (ng/L) }\end{array}$ & $\begin{array}{c}\text { Control } \\
\text { value }\end{array}$ & Mean \\
\hline Low & $12-28$ & 19.1 & 19.45 \\
Medium & $120-280$ & 19.8 & \\
& & 189 & 193 \\
High & $9,000-21,000$ & 197 & \\
& & $15,903.3$ & 15,564 \\
\hline
\end{tabular}

assayed immediately after centrifugation for hs-cTnl, cTnl, lipid profile and creatinine. $\mathrm{HbA}_{1 \mathrm{c}}$ was determined immediately after delivery in whole blood and BNP was measured in fresh EDTA plasma. All measurements were performed on the Abbott ARCHITECT ci8200 analyzer. The remaining material was separated in small aliquots and frozen at $-70^{\circ} \mathrm{C}$.

Estimated GFR (eGFR) was calculated using Modification of Diet in Renal Disease (MDRD) formula which estimates GFR using four variables: serum creatinine, age, race, and gender [9].

\section{Statistical analysis}

The $99^{\text {th }}$ percentile values were determined by right-sided nonparametric statistics as described in the CLSI C28-A3 [10]. 90\% confidence intervals (Cl) were given if possible. We decided to exclude the outlier observations from the analyzed population using the method of Reed et al. [11]. The reference intervals were calculated using a non-parametrical percentile method. Statistical analysis was performed using MedCalc 12.7.0.

\section{Results}

Analytical performance

Familiarization. Initially, we measured three levels of STAT hsTnl Control on the Abbott ARCHITECT ci8200 analyzer in replicates of two. None of the control measurements exceeded dedicated control levels (Tab. 1).

Precision. The precision study was performed on each of 5 days according to CLSI guidelines (EP5-A) [5]. Two ARCHITECT runs were performed on each day with a minimum of $2 \mathrm{~h}$ separating the runs. Three Troponin-I controls were assayed in replicates of two on each run ( $n=20$ total reps for each control). Total imprecision ranged from $3.1 \%$ to $5.1 \%$ and was lowest for the medium controls. The lowest hs-cTnl concentration corresponding to a total CV of $10 \%$ was $5.2 \mathrm{ng} / \mathrm{L}$. The obtained results are shown in Table 2.

LoB, LoD and LOQ. Verification of LoB, LoD and LoQ was performed according to CLSI guidelines EP17-A on verifying LoB, LoD and LoQ [6]. The LoB was determined by twenty measurements of the zero calibrator. Only two replicates exceeded the claimed LoB. The nonparametric analysis showed the $95^{\text {th }}$ percentile value equal to 0.1 . The LoD was determined using twenty replicates of a sample with concentration equal to the claimed LoD. The mean LoD value was $1.5 \mathrm{ng} / \mathrm{L}(19 \% \mathrm{CV})$. The LoQ was determined using 30 replicates of a sample with a concentration close to the claimed LoQ. The mean LoQ value was 4.8 (8\% CV).

Dilution linearity. The linearity of cTnl assay was verified using low and high cTnl pools. Then we mixed in a 1:1 ratio high and low cTnl, and its concentration was determined. There was no dilution effect on the concentration of troponin. 
Table 2. Results of the five-day precision study

\begin{tabular}{|c|c|c|c|}
\hline Day & $\begin{array}{c}\text { Control level } \\
\text { Low } \\
\text { [ng/L] }\end{array}$ & $\begin{array}{c}\text { Control level } \\
\text { Medium } \\
\text { [ng/L] }\end{array}$ & $\begin{array}{c}\text { Control level } \\
\text { High } \\
\text { [ng/L] }\end{array}$ \\
\hline 1 & $\begin{array}{l}20.4 \\
19.5\end{array}$ & $\begin{array}{l}186.9 \\
185.4\end{array}$ & $\begin{array}{l}15,243.6 \\
15,759.7\end{array}$ \\
\hline $1+\min .2 \mathrm{~h}$ & $\begin{array}{l}19.8 \\
19.1\end{array}$ & $\begin{array}{l}197 \\
189\end{array}$ & $\begin{array}{l}15,224.8 \\
15,906.3\end{array}$ \\
\hline 2 & $\begin{array}{l}18.8 \\
19.4\end{array}$ & $\begin{array}{l}196.6 \\
190.4\end{array}$ & $\begin{array}{l}15,199.1 \\
16,015.3\end{array}$ \\
\hline $2+\min .2 h$ & $\begin{array}{l}17.9 \\
18.4\end{array}$ & $\begin{array}{l}178.6 \\
187.3\end{array}$ & $\begin{array}{l}15,248.3 \\
15,466.8\end{array}$ \\
\hline 3 & $\begin{array}{l}19.7 \\
21.1\end{array}$ & $\begin{array}{l}187.6 \\
194.6\end{array}$ & $\begin{array}{l}15,755.2 \\
16,064.2\end{array}$ \\
\hline $3+\min .2 h$ & $\begin{array}{l}17.9 \\
19.4\end{array}$ & $\begin{array}{l}191.8 \\
199.7\end{array}$ & $\begin{array}{l}15,505.6 \\
15,863.0\end{array}$ \\
\hline 4 & $\begin{array}{l}17.5 \\
17.4\end{array}$ & $\begin{array}{l}179.9 \\
182.4\end{array}$ & $\begin{array}{l}13,815.9 \\
14,235.7\end{array}$ \\
\hline $4+\min .2 h$ & $\begin{array}{l}18.4 \\
18.8\end{array}$ & $\begin{array}{l}185.7 \\
185.6\end{array}$ & $\begin{array}{l}14,211.5 \\
14,173.3\end{array}$ \\
\hline 5 & $\begin{array}{l}18.4 \\
18.3\end{array}$ & $\begin{array}{l}182.8 \\
185.7\end{array}$ & $\begin{array}{l}15,369.0 \\
14,512.5\end{array}$ \\
\hline $5+\min .2 h$ & $\begin{array}{c}18 \\
18.3\end{array}$ & $\begin{array}{l}180.7 \\
183.2\end{array}$ & $\begin{array}{l}14,158.6 \\
14,635.7\end{array}$ \\
\hline Mean \pm SD [ng/L] & $18.8 \pm 0.96$ & $187.5 \pm 5.92$ & $15118.2 \pm 717.7$ \\
\hline CV(\%) & 5.1 & 3.1 & 4.7 \\
\hline
\end{tabular}

SD — standard deviation; CV — coefficient of variation

Interference testing. The evaluation of interference was performed using a native sample with TG in a concentration of about $2000 \mathrm{mg} / \mathrm{dL}$. Pools of cTnl of various concentrations were mixed with a serum sample of a patient in order to achieve a $1000 \mathrm{mg} / \mathrm{dL}$ concentration of TG. There was no effect of high TG concentrations on cTnl concentration.

\section{Determination of $99^{\text {th }}$ percentile values}

Table 3 reports $99^{\text {th }}$ percentile values with $90 \% \mathrm{Cl}$ for the Abbott Architect STAT hs-cTnl in presumably healthy individuals $(n=419)$. When statistical criteria for outliers were applied, data for 3 study participants were excluded, which lowered the $99^{\text {th }}$ percentile value to $12.6 \mathrm{ng} / \mathrm{L}$ (8.4-24.3; 90\% Cl) from $15.6 \mathrm{ng} / \mathrm{mL}(9.7-33.8 ; 90 \% \mathrm{Cl})$. The $99^{\text {th }}$ percentile values were more than twice as high in males compared to females. In young women and men ( $<40$ years) we observed similar $99^{\text {th }}$ percentile values, in contrast to the older group ( $>40$ years), in which men were characterized by almost twice as high $99^{\text {th }}$ percentile value than women.

After the introduction of laboratory screening in accordance with the predefined selection criteria, 98 patients were excluded. The results for the group of healthy individuals are shown in Table 4. As expected, after the inclusion of more restrictive criteria the 99th percentile values decreased to $10.6 \mathrm{ng} / \mathrm{mL}$ (8-12.9; $90 \% \mathrm{Cl}$ ). $99^{\text {th }}$ percentile values for hs-cTnl were quite similar in healthy men and women, showing a slight increase in women. Unexpectedly, older women were characterized with higher hs-cTnl $99^{\text {th }}$ percentile value, when compared to men.

Finally, we examined hs-cTnl $99^{\text {th }}$ percentile URLs in subjects remaining after screening for dyslipidemia (Tab. 5). Following the introduction of this criterion, 184 individuals were excluded. Of the 320 healthy individuals only $42 \%$ had normal lipid profile values. These group consisted of 106 women and only 30 men, and was characterized by the lowest $99^{\text {th }}$ percentile URLs for hs-cTnl with a slightly higher $99^{\text {th }}$ percentile value in men.

\section{Method comparison using Passing-Bablok regression}

We also conducted a comparison of Abbott ARCHITECT STAT high sensitive Troponin-I assay with Abbott ARCHITECT STAT Troponin-I assay using Passing-Bablok linear regression, which showed that the two methods are comparable. We used 200 specimens 
Table 3. $99^{\text {th }}$ percentile values in presumably healthy individuals

\begin{tabular}{lcc}
\hline hs-cTnl [ng/L] & $\mathbf{Q 2}(\mathbf{Q 1}-\mathbf{Q 3})$ & $\mathbf{9 9}^{\text {th }}$ percentile value $(\mathbf{9 0} \% \mathbf{C I})$ \\
\hline Presumably healthy individuals $(\mathrm{n}=418)$ & $2.7(2.1-3.5)$ & $12.6(8.4-24.3)$ \\
Women $(\mathrm{n}=265)$ & $2.5(2-3.1)$ & 10.2 \\
Men $(\mathrm{n}=153)$ & $3.3(2.5-4.7)$ & 22.1 \\
Women $<40$ years $(\mathrm{n}=133)$ & $2.3(1.8-2.8)$ & 9.1 \\
Men $<40$ years $(\mathrm{n}=67)$ & $2.6(2.2-3.5)$ & 10.9 \\
Women $\geq 40$ years $(\mathrm{n}=132)$ & $2.7(2.2-3.3)$ & 12.4 \\
Men $\geq 40$ years $(\mathrm{n}=86)$ & $4.0(3-5.2)$ & 24.3 \\
\hline
\end{tabular}

$\mathrm{Cl}$ - confidence interval; hs-cTnl — high-sensitivity cardiac troponin I; Q1 — lower quartile; Q2 — median; Q3 — upper quartile

Table 4. $99^{\text {th }}$ percentile values in healthy individuals

\begin{tabular}{lcc}
\hline hs-cTnl $(\mathbf{n g} / \mathbf{L})$ & $\mathbf{Q 2}(\mathbf{Q 1}-\mathbf{Q 3})$ & 99 \\
\hline Healthy individuals $(\mathrm{n}=320)$ & $2.6(2.1-3.4)$ & $10.6(8-12.9)$ \\
Women $(\mathrm{n}=212)$ & $2.4(1.9-3.1)$ & 11.1 \\
Men $(\mathrm{n}=108)$ & $3.3(2.5-4.5)$ & 10.7 \\
Women $<40$ years $(\mathrm{n}=118)$ & $2.2(1.8-3.2)$ & 9.4 \\
Men $<40$ years $(\mathrm{n}=57)$ & $2.6(2.2-3.5)$ & 10.9 \\
Women $\geq 40$ years $(\mathrm{n}=94)^{*}$ & $2.6(2.2-3.2)$ & 12.9 \\
Men $\geq 40$ years $(\mathrm{n}=49)$ & $4.2(3.2-4.9)$ & 8.9 \\
\hline
\end{tabular}

*One of the results of hs-cTnl was $12.9 \mathrm{ng} / \mathrm{L}$, but according to the method of Reed it has not been interpreted as an outlier.

$\mathrm{Cl}$ - confidence interval; hs-cTnl - high-sensitivity cardiac troponin I; Q1 — lower quartile; Q2 — median; Q3 - upper quartile

Table 5. $99^{\text {th }}$ percentile values in healthy individuals with normal lipid profile

\begin{tabular}{lcc}
\hline hs-cTnl [ng/L] & Q2 (Q1-Q3) & $\begin{array}{c}\mathbf{9 9}^{\text {th }} \\
\text { percentile } \\
\text { value }\end{array}$ \\
\hline $\begin{array}{l}\text { Healthy individuals with normal } \\
\text { lipid profile } \\
(\mathrm{n}=136)\end{array}$ & $2.3(1.9-3.2)$ & 8.6 \\
Women $(\mathrm{n}=106)$ & $2.3(1.8-3)$ & 7.9 \\
Men $(\mathrm{n}=30)$ & $3.2(2.3-4.6)$ & 8.9
\end{tabular}

$\mathrm{Cl}$ - confidence interval; hs-cTnl — high-sensitivity cardiac troponin I Q1 - lower quartile; Q2 - median; Q3 - upper quartile

with cTnl concentrations across the dynamic range of the ARCHITECT STAT High Sensitive Troponin-I assay. The results are shown in Figure 2 and Table 6.

\section{Discussion}

The FAM study conducted by our department was unique for several reasons. Firstly, the blood sampling from presumably healthy individuals was held in several workplaces across the region. Secondly, all measurements were performed in fresh, not frozen material, immediately after delivery of samples to the laboratory. Thirdly, presumably healthy and healthy individuals

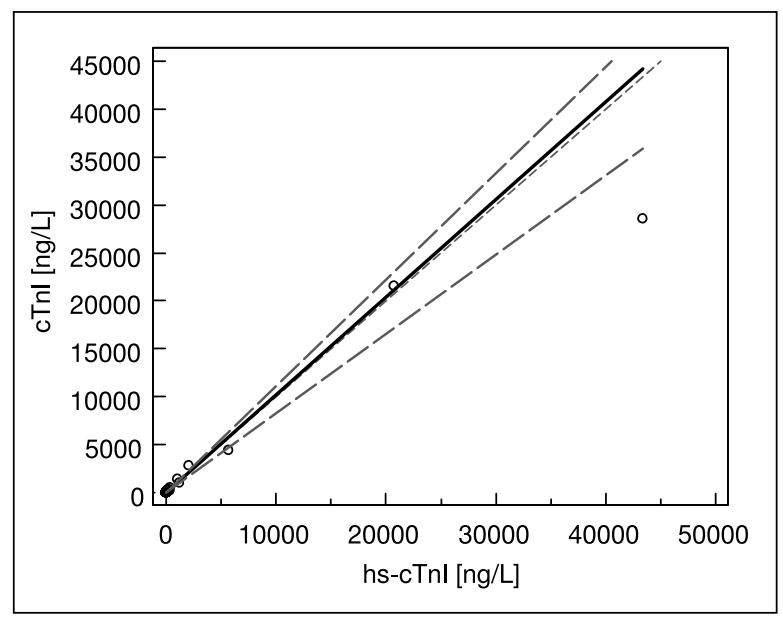

Figure 2. The scatter diagram for comparison of the Abbott ARCHITECT STAT High Sensitive Troponin-I assay and the Abbott ARCHITECT STAT Troponin-I assay using the Passing-Bablok regression (with the regression line- solid line, the confidence interval for the regression line - dashed lines and identity line $x=y$, dotted line); hs-cTnl - high sensitivity cardiac troponin I; cTnl — cardiac troponin I

were selected for the reference interval study on the basis of a questionnaire and additional laboratory screening. Finally, we determined age and sex-specific 99th percentile URLs for hs-cTnl. 
Table 6. The ARCHITECT STAT High Sensitive Troponin-I assay and the ARCHITECT STAT Troponin-I assay method comparison

\begin{tabular}{lccc}
\hline \multicolumn{4}{l}{ Correlation Coefficient $(\boldsymbol{r})$} \\
\hline $\mathbf{R}$ & $95 \% \mathrm{Cl}$ & Slope & $95 \% \mathrm{Cl}$ \\
0.9796 & $0.9732-0.9846$ & 1.0046 & $0.8696-1.0860$ \\
\hline
\end{tabular}

To ensure that the hs-cTnl assay is fit for purpose we performed studies on the LoB, LoD and LoQ values which demonstrated a slight variability with other studies [12, 13]. The lowest concentration of cTnl detected with $99 \%$ probability was $1.5 \mathrm{ng} / \mathrm{L}$, whereas estimated LoB was predominantly below 0.1 . The newer hs-cTn assay is more analytically sensitive than the previous generation of cTnl assays, highlighting the need for LoD to be reported [14].

Our study showed detectable hs-cTnl concentrations in a majority of presumably healthy individuals $(98 \%)$ in contrast to other studies [12]. The Abbott ARCHITECT STAT high sensitive troponin-I assay in this and our previous studies $[15,16]$ performed better in terms of cTnl detectability than other commercially available hs-cTn assays [17]. Of importance, these results should be interpreted with caution as the proportion of subjects with detectable concentrations of hs-cTn substantially depends on the characteristics of the population. The $99^{\text {th }}$ percentile URL differed depending on the conditions of selection criteria applied in the presumably healthy population. The highest $99^{\text {th }}$ percentile value was reported for presumably healthy individuals who participated in the study based on their health questionnaires. In these presumably healthy individuals, men were characterized by having nearly twice as high $99^{\text {th }}$ percentile values, when compared to women, which was particularly evident in the older group above 40 years of age. In the younger group of both women and men $99^{\text {th }}$ percentile values were quite similar with only slight predominance in males, which may suggest that the differences in cTnl concentrations accumulate with age. In the course of further analysis presumably healthy individuals were screened by more stringent criteria, including laboratory parameters, and the $99^{\text {th }}$ percentile values decreased with further screening. Similar observations concerning the influence of population selection on the $99^{\text {th }}$ percentile reference values for cTn were also reported in other studies [16, 18]. Interestingly, in our study we showed that after the inclusion of more stringent selection criteria, the differences between sex and age of the healthy individuals were reduced. Despite the lower $99^{\text {th }}$ percentile values in the female subgroup, the imprecision goal below $10 \%$ CV was maintained. These findings are of particular importance with regard to the clinical application of hs-cTnl using sex specific cut-offs. Lowering the diagnostic threshold for hs-cTnl when compared with the contemporary cTnl is expected to facilitate the decision making process in different clinical settings [18].

In summary, our study provides the analytical characteristics of the Abbott ARCHITECT STAT high sensitive troponin-I immunoassay in relation to guideline recommendations, along with its strengths of improved precision and low-end sensitivity. Additionally, we established its $99^{\text {th }}$ percentile URLs, overall URL, age and sex-specific URLs.

\section{References}

1. The Joint European Society of Cardiology/American College of Cardiology Committee. Myocardial infarction redefined - A consensus document of the Joint European Society of Cardiology/American College of Cardiology Committee for the Redefinition of Myocardial Infarction. Eur Heart J 2000; 21: 1502-1513

2. Thygesen K, Alpert JS, White HD; Joint ESC/ACCF/AHAMHF Task Force for the Redefinition of Myocardial Infarction. Universal definition of myocardial infarction. Eur Heart J 2007; 28: 2525-2538.

3. Thygesen K, Alpert JS, Jaffe AS et al. Third universal definition of myocardial infarction. Eur Heart J 2012; 33: 2551-2567.

4. Roffi M, Patrono C, Collet JP et al. 2015 ESC Guidelines for the management of acute coronary syndromes in patients presenting without persistent ST-segment elevation: Task Force for the Management of Acute Coronary Syndromes in Patients Presenting without Persistent ST-Segment Elevation of the European Society of Cardiology (ESC). Eur Heart J 2015 Aug 29. pii: ehv320 [Epub ahead of print].

5. Clinical Laboratory Standards Institute. Evaluation of precision performance of quantitative measurement methods; approved guidelines, EP5-A2. Wayne, PA: Clinical and Laboratory Standards Institute, 2004.

6. Clinical Laboratory Standards Institute. Evaluation of detection capability for clinical laboratory measurement procedures; approved guidelines, 2nd ed, EP17-A2. Wayne, PA: Clinical and Laboratory Standard Institute, 2012.

7. Clinical Laboratory Standards Institute. Evaluation of the linearity of quantitative measurement procedures: a statistical approach; approved guidelines, EP6-A. Wayne, PA: Clinical and Laboratory Standards Institute, 2003

8. Third Report of the National Cholesterol Education Program (NCEP) expert panel on detection, evaluation, and treatment of high blood cholesterol in adults (Adult Treatment Panel III) final report. Circulation 2002; 25: 3143-3421.

9. K/DOQI clinical practice guidelines for chronic kidney disease: evaluation, classification, and stratification. Am J Kidney Dis. 2002; 39: S1-S266

10. Defining, establishing, and varifying reference intervals in the clinical laboratory: approved guidline-third edition. CLSI C28-3. 2008.

11. Reed AH, Henry RJ, Mason WB. Influence of statistical method used on the resulting estimate of normal range. Clin Chem 1971; 17: 275-284.

12. Apple FS, Ler R, Murakami MM. Determination of 19 cardiac troponin I and $T$ assay 99th percentile values from a common presumably healthy population. Clin Chem 2012; 58: 1574-1781.

13. Koerbin G, Tate J, Potter JM, Cavanaugh J, Glasgow N, Hickman PE. Characterisation of a highly sensitive troponin I assay and its application to a cardio-healthy population. Clin Chem Lab Med 2012; 50: $871-878$

14. International Federation of Clinical Chemistry and Laboratory Medicine. Troponin assay analytical characteristics 2013. Available from: http:// www.ifcc.org/media/245272/IFCC\%20Troponin\%20l\%20and\%20 T\%20\%28ug_L\%20units\%29\%20_update\%20December\%202013. pdf. Accessed 1 May, 2014.

15. Krintus M, Kozinski M, Boudry P et al. European multicenter analytical evaluation of the Abbott ARCHITECT STAT high sensitive troponin I immunoassay. Clin Chem Lab Med 2014; 52: 1657-1665.

16. Krintus $M$, Kozinski $M$, Boudry $P$ et al. Defining normality in a European multinational cohort: Critical factors influencing the 99th percentile upper reference limit for high sensitivity cardiac troponin I. Int J Cardiol. 2015; 187: 256-263

17. Saenger AK, Beyrau R, Braun S et al. Multicenter analytical evaluation of a high-sensitivity troponin T assay. Clin Chim Acta 2011; 412: 748-754.

18. Collinson PO, Heung YM, Gaze D, Boa F, Senior R, Christenson R, Apple FS. Influence of population selection on the 99th percentile reference value for cardiac troponin assays. Clin Chem 2012; 58: 219-225. 